\title{
Role of Radiofrequency Ablation in the Management of Unresectable Pancreatic Cancer
}

\author{
Muhammad Nadeem Yousaf ${ }^{1,2,3,4 *}$, Hamid Ehsan ${ }^{1}$, Ahmad Muneeb ${ }^{5}$, Ahsan Wahab ${ }^{6}$, \\ Muhammad K. Sana ${ }^{7}$, Karun Neupane ${ }^{8}$ and Fizah S. Chaudhary ${ }^{1,2,3,4}$ \\ ${ }^{1}$ Department of Medicine, MedStar Union Memorial Hospital, Baltimore, MD, United States, ${ }^{2}$ MedStar Franklin Square \\ Medical Center, Baltimore, MD, United States, ${ }^{3}$ MedStar Good Samaritan Hospital, Baltimore, MD, United States, ${ }^{4}$ MedStar \\ Harbor Hospital, Baltimore, MD, United States, ${ }^{5}$ Department of Medicine, Faisalabad Medical University, Faisalabad, \\ Pakistan, ${ }^{6}$ Department of Medicine, Baptist Medical Center South, Montgomery, AL, United States, ${ }^{7}$ Department of \\ Medicine, King Edward Medical University, Lahore, Pakistan, ${ }^{8}$ Department of Medicine, Manipal College of Medical \\ Sciences, Pokhara, Nepal
}

\section{OPEN ACCESS}

Edited by:

Abhilash Perisetti,

University of Arkansas for Medical Sciences, United States

Reviewed by:

Alessandro Giardino,

Casa di cura Pederzoli, Italy Stefano Francesco Crinò,

University of Verona, Italy

*Correspondence:

Muhammad Nadeem Yousaf nadeem.yousaf200@gmail.com

\footnotetext{
Specialty section:

This article was submitted to

Gastroenterology,

a section of the journal

Frontiers in Medicine
}

Received: 02 November 2020 Accepted: 11 December 2020

Published: 11 February 2021

Citation:

Yousaf MN, Ehsan H, Muneeb A, Wahab A, Sana MK, Neupane K and Chaudhary FS (2021) Role of Radiofrequency Ablation in the Management of Unresectable Pancreatic Cancer. Front. Med. 7:624997. doi: 10.3389/fmed.2020.624997
Pancreatic cancer is one of the most aggressive malignancies of the digestive tract and carries a poor prognosis. The majority of patients have advanced disease at the time of diagnosis. Surgical resection offers the only curative treatment, but only a small proportion of patients can undergo surgical resection. Radiofrequency ablation (RFA) is a well-known modality in the management of solid organ tumors, however, its utility in the management of pancreatic cancer is under investigation. Since the past decade, there is increasing use of RFA as it provides a feasible palliation treatment in the management of unresectable pancreatic cancer. RFA causes tumor cytoreduction through multiple mechanisms such as coagulative necrosis, protein denaturation, and activation of anticancer immunity. The safety profile of RFA is controversial because of the high risk for complications, however, small prospective and retrospective studies have shown promising results in its applicability for palliative management of unresectable pancreatic malignancies. In this review, we discuss different approaches of RFA, their indications, technical accessibility, safety, and major complications in the management of unresectable pancreatic cancer.

Keywords: pancreatic cancer, radiofrequency ablation, endoscopic ultrasound, endoscopic retrograde cholangiopancreatography, palliative cancer care

\section{INTRODUCTION}

Pancreatic cancer is one of the most aggressive gastrointestinal malignancies and is the fourth leading cause of mortality in the United States despite advancement in both diagnostic and therapeutic interventions in the management of these patients. Annual incidence of pancreatic cancer in the United States is $\sim 57,600$ cases, while estimated mortality rate is 47,050 with a slight male predominance (1). Pancreatic cancer has a poor prognosis with a 5 years relative survival rate of only $9 \%$ (1). Surgical resection provides the only potential curative option in pancreatic cancer patients (2). However, only $15-20 \%$ of the patients with pancreatic cancer are eligible for surgical resection, as majority of them present with locally advanced stages or with distant metastasis when surgical resection is not possible (3). A multimodality approach is required in the management of pancreatic cancer even in patients undergoing surgical resection for curative intent. A multimodal approach involves the systemic chemotherapy (adjuvant/neoadjuvant), local ablation and surgical resection (depending upon the staging of pancreatic tumor) (4). Adjuvant treatment is an important part of management in those patients who have 
undergone surgical resection since the 5-year survival rate in these patients is only around $20 \%$ (4). Patients with unresectable pancreatic cancer have a median survival of only 11-15 months after chemoradiation (3, 5). In comparison, the survival rate extends to 22-26 months after surgical resection, adjuvant or neoadjuvant chemotherapy $(3,5)$. For patients with unresectable pancreatic cancer, palliation with chemoradiation therapy and endoscopic interventions are utilized to improve quality of life. However, these palliative treatments barely change the outcome of disease. In addition to chemoradiation, various modalities (matrix metalloproteinases, targeted therapies, angiogenesis inhibitors, epidermal growth factor receptor inhibitors, and immunotherapies) are emerging for the treatment of patients with pancreatic adenocarcinoma (4). Radiofrequency ablation (RFA) is a well-known modality that has been used effectively for the treatment of solid tumors, such as hepatocellular cancer, cholangiocarcinoma, malignancies involving lungs, breast, kidney, bones, and prostrate $(6,7)$. RFA has been found to be superior to percutaneous ethanol injection with overall survival rates of $55 \%$ vs. $42 \%$, respectively $(p<0.01)$ in patients with unresectable stage I-II hepatocellular carcinoma (8). RFA has also been found to be effective in the treatment of intrahepatic cholangiocarcinoma of $3 \mathrm{~cm}$ or less with complete necrosis seen in $100 \%$ patients (9). However, the definitive role of RFA for pancreatic cancer remains under investigation. Implementation of RFA in the management of unresectable pancreatic cancer is a relatively newer treatment option that may potentially provide an effective palliation in these patients due to cytoreduction of tumor (10). In addition to thermal effect, it is proposed that RFA triggers antitumor immunity by activating cancer specific T lymphocytes and heat shock protein-70 $(11,12)$. The efficacy and safety of RFA procedure is unclear in literature. In this review, we provided an overview of RFA and discussed various approaches of RFA therapies in the management of pancreatic cancer. To identify the relevant published literature, we performed a comprehensive search on PubMed, Google Scholar, Cochrane, Clinicaltrials.gov, and browsed through the references of relevant studies using the MeSH terms "pancreatic cancer" and "radiofrequency catheter ablation."

\section{PRINCIPLES AND PROTOCOL OF RADIOFREQUENCY ABLATION THERAPY}

Radiofrequency ablation involves delivery of thermal energy to the tumor through special needle electrodes that leads to coagulative necrosis with protein denaturation and decreased tumor bulk (13). Human cells cannot withstand temperature above $50^{\circ} \mathrm{C}$ and start undergoing denaturation. Temperature as high as $60^{\circ} \mathrm{C}$ results in cell death (14). Application of the high frequency alternating current $(200-1,200 \mathrm{kHz}$ frequency) via an electrode causes an agitation of positive and negatively charged ions within the tissue and produce additional heat due to friction. Heat production is maximum in the area around the electrode because of a high flow of electrical current. This heat energy results in coagulative necrosis of the tumor eventually leading to reduction of tumor volume $(15,16)$. The protocol to use RFA therapy in the management of hepatocellular or cholangiocarcinoma is well-established in the current practice guidelines (17). Such protocol to use RFA therapy for pancreatic cancer does not exist in the current practice guidelines because of lack of sufficient data. Current use of RFA in pancreatic cancer is based on the individual experiences of expertise and medical center specific protocols. Precise control of temperature, frequency of current, and duration of the delivery of alternating current is crucial as uncontrolled heat can lead to excessive charring resulting in circuit break. In the event of large tumor bulk, charring can be controlled with the use of saline irrigation (18). A recommended safe temperature for RFA is $90^{\circ} \mathrm{C}$ (mean) as temperature higher than $105^{\circ} \mathrm{C}$ results in increased risk of adverse events without favorable impact on tumor size.

\section{RADIOFREQUENCY ABLATION TECHNIQUES}

RFA of pancreatic tumors can be performed using different approaches, that include the intraoperative approach, percutaneous approach under ultrasound or radiologic imaging guidance, an endoscopic approach using endoscopic ultrasound (EUS) or endoscopic retrograde cholangiopancreatography (ERCP). RFA poses a risk of potential adverse events both to surrounding vital structures as well as pancreas itself. Common potential adverse events associated with RFA therapy are acute pancreatitis, pancreatic fistula, gastrointestinal hemorrhage, sepsis, portal vein thrombosis, and damage to surrounding structures, such as duodenum or bile duct (19). However, the risk of these adverse events is low with modifications of RFA techniques, such as altering ablation parameters like ablation temperature, distance of RFA needle from adjoining structures, and introducing other safety measures like duodenal and inferior vena cava cooling during ablation (20-22).

\section{INTRAOPERATIVE RADIOFREQUENCY ABLATION}

\section{Indications and Technical Accessibility}

Intraoperative RFA is indicated in unresectable, non-metastatic and locally advanced pancreatic tumor involving pancreatic head or uncinate process that results in either obstructive jaundice or gastric outlet obstruction. It is also performed in patients who are found to be inoperable during surgery or those who are not amenable to percutaneous imaging guided or endoscopic guided interventions for palliation (7, 23-25). Intraoperative RFA involves thermal ablation of tumor during laparotomy. If tumor involves pancreatic head, Kocher maneuver is performed to expose head of the pancreas. Continuous cooling is used to prevent thermal damage to the surrounding structures. For cooling of duodenum, a nasogastric tube is placed in the proximal duodenum and cold saline is irrigated continuously. Cold gauze can be placed over inferior vena cava to protect it from thermal injury. RFA needle is inserted under ultrasonographic guidance during surgery to avoid damage to the nearby vital structures. Thermal energy is delivered after positioning the specialized 
RFA needle in the middle of the tumor. A safe needle distance from the duodenum and other surrounding structures should be maintained to prevent thermal damage to these structures $(7,25,26)$.

\section{Safety and Adverse Events}

Hlavsa et al. compared 24 patients with intraoperative RFA (intervention group) with 24 patients who underwent only surgical bypass procedure and reported lower rate of 3 months mortality of 16.6 vs. $41.7 \%$, comparable morbidity of $8.3 \%$, and relatively higher overall median survival 9.9 vs. 8.3 months in RFA group compared with control group $(p=0.758)(25)$. Median survival was better among patients with grade I and II tumors after RFA than grade III tumor (25). Although results of this study did not show significant survival benefits, however, RFA appears to be feasible palliative option in welldifferentiated unresectable pancreatic cancer. In a small study of 4 patients with locally advanced unresectable pancreatic cancer, no difference of survival was noted after intraoperative RFA, however, CA 19-9 tumor marker was decreased in all patients without adverse events at 12 months follow up (7). Zou et al. used a modified technique with a combination of an intraoperative RFA and implantation of radioactive iodine $\left(\mathrm{I}^{125}\right)$ seed within the pancreatic tumor in 32 patients that resulted in the improvement in quality of life with a decreased median pain score (from 5.86 \pm 1.92 to $2.65 \pm 1.04$ ) at 1 month and an increased survival time upto 17.5 months that was longer for stage III cancer as compared to stage IV cancer (27). A combined complete or partial regression of tumor was noted in $78.1 \%$ of patients, while $15.6 \%$ patients did not respond to this approach (27).

Common adverse events associated with intraoperative RFA are gastrointestinal bleeding, acute pancreatitis, biliary or pancreatic duct fistula, biliary leak, and post-operative wound or intra-abdominal infections. Matsui et al. used intraoperative RFA in 20 patients with high technical and clinical success of procedure as decrease in serum tumor markers was found in 14 patients and two patients experienced serious adverse events, such as septic shock and gastrointestinal hemorrhage (23). Varshney et al. reported partial necrosis (up to $3 \mathrm{~cm}$ ) of the tumors with RFA in three patients with inoperable pancreatic adenocarcinoma and minor self-limiting adverse events in two patients (10). Wu et al. assessed the safety of cool tip RFA in 16 pancreatic cancer patients and recommended a distance between RFA site and major peripancreatic vessels should be $>5 \mathrm{~mm}$ as mortality rate of $25 \%$ was noted in patients with tumor closer to portal vein (24). In a study of 50 patients, 30 days mortality rate was only $2 \%$ with intraoperative RFA and a significant reduction of procedure related complications was noted by decreasing RFA temperature from 105 to $90^{\circ} \mathrm{C}$. In this study only 6/50 patients experienced RFA related adverse events, such as pancreatic fistulas (two patients), portal vein thrombosis (four patients), duodenal bleeding (two patients), and pancreatitis (one patient) (22). In a larger study of 265 patients, overall morbidity and mortality were $23.4 \%(62 / 265)$ and $1.5 \%$ however, a higher rate of RFA-related adverse events $12.8 \%(34 / 265)$ was found as compared to overall surgical adverse events $10.4 \%$ (28/265). Overall survival, disease-specific survival and progression-free survival of first 200 patients as reported by an interim analysis were, 19,19 , and 13 months, respectively $(28,29)$.

\section{PERCUTANEOUS RADIOFREQUENCY ABLATION}

\section{Indications and Technical Accessibility}

Percutaneous RFA is indicated in selected number of patients with locally advanced and unresectable pancreatic cancer without evidence of metastasis. Percutaneous RFA is a minimally invasive technique that involves percutaneous passage of RFA needle into malignant lesion under guidance of an abdominal ultrasound or radiological imaging, such as CT scan which is performed before the procedure to assess the accessibility of the lesion and technical feasibility of the procedure. After confirming the potential route of RFA needle, it is advanced into the lesion. Effort is made to avoid damage to the adjacent blood vessels and surrounding structures. RFA electrodes are then positioned in the center of the tumor and thermal energy is delivered for ablation of tumor. A real time monitoring of thermal effect of RFA on tumor and surrounding structures can be seen with ultrasound. Ablation time, power and other parameters are adjusted according to the tumor size and tissue impedance (30).

\section{Safety and Adverse Events}

In a small pilot study of eight patients with neuroendocrine unresectable pancreatic cancer, ultrasound guided percutaneous RFA was performed in seven patients and a high clinical success of procedure as tumor regression was noted in all patients on median follow up of 34 months without any mortality (31). Similar results of safety and feasibility of CT scan-guided RFA was reported in several studies (Table 1) (30-35). D'Onofrio et al. assessed the feasibility and effectiveness of percutaneous RFA in 18 patients with non-metastatic unresectable pancreatic adenocarcinoma and achieved a technical success of $93 \%$ in 16 out of 18 patients with a mean survival of 185 days (range 62-398 days) (30). The tumor size remained stable in 55.6\% $(10 / 18)$ of patients at 1 month of follow up abdominal CT scan, and increased in $44.4 \%(8 / 18)$ patients which raised question about the effectiveness of percutaneous RFA (30). Mizandari et al. performed percutaneous intraluminal RFA coupled with stent placement was used in 134 patients with malignant obstructions of bile and pancreatic ducts (32 patients with pancreatic adenocarcinoma) and reported a $97 \%$ success rate of procedure with only two patients experienced procedural technique related adverse events (contrast extravasation) following RFA (36).

\section{ENDOSCOPIC-GUIDED RADIOFREQUENCY ABLATION}

\section{Indications and Technical Accessibility}

EUS and fluoroscopic-guided radiofrequency ablation (RFA) can also be used to ablate locally advanced neoplastic lesions that have not yet metastasized $(37,38)$. In the past decade, there is increasing use of endoscopic-guided RFA for unresectable pancreatic adenocarcinoma, resectable tumors in patients 


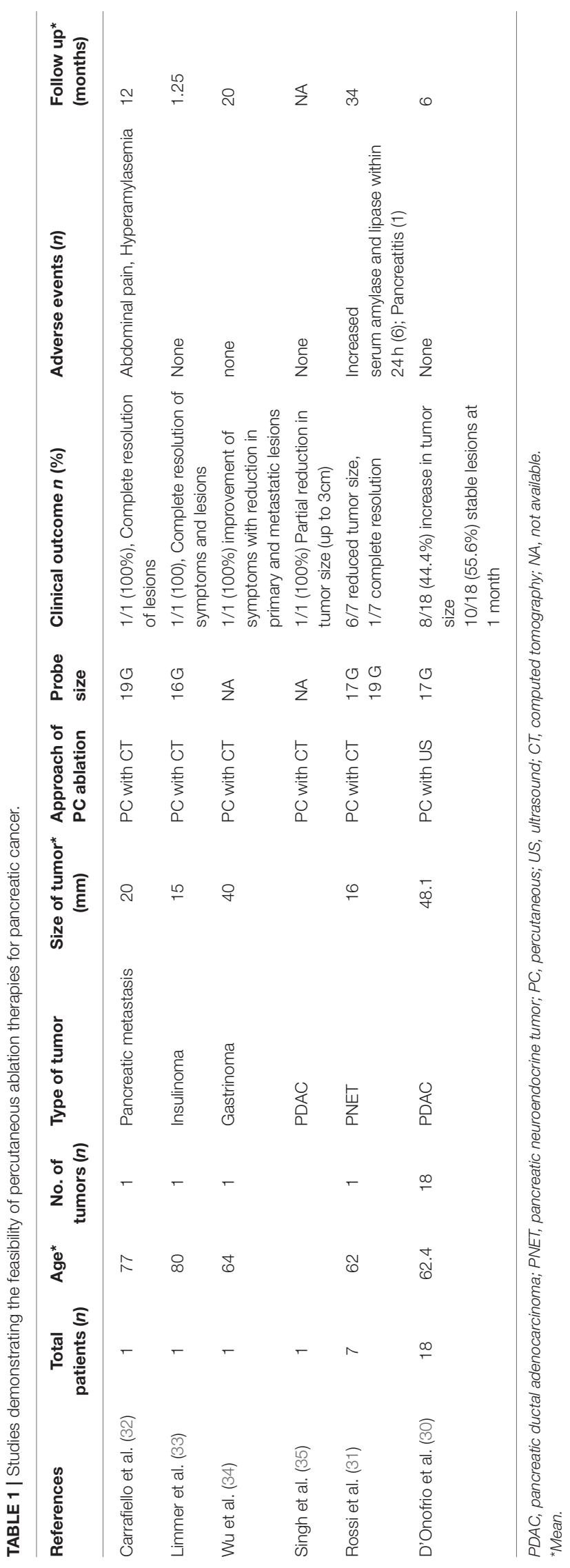

that cannot undergo surgery or chemotherapy because of comorbidities and those patients who are not responsive to other therapies $(39,40)$. Endoscopic-guided RFA is also a minimally invasive approach that involves positioning of duodenoscope in the stomach or duodenum closer to the pancreatic tumor and passage of an electrode needle into the tumor under endoscopic guidance for tumor ablation. This technique involves the application of a high-frequency probe around the malignant tissue, causing coagulative necrosis from radiofrequency-induced hyperthermia. Specifically, for pancreatic cancer, commercially available RFA probes are available that are advanced over 0.035inch guidewire through a specialized catheter compatible with standard ERCP or EUS duodenoscope (41). Endoscopic-RFA is commonly used for the treatment of stage III pancreatic adenocarcinoma and should be considered in the management of locally advanced or unresectable pancreatic cancers in the absence of distant metastases (42). It has been used as initial management at the time of diagnosis, as combined therapy and in case of failure of standard systemic treatment options $(13,38,43)$. Stage IV patients have also been included in a few studies with some benefit $(24,44)$.

Care is taken during insertion of RFA probe to avoid damage to normal parenchyma and surrounding structures including pancreatic or bile duct and major blood vessels adjacent to tumor. The needle tip is placed at the distal end inside the tumor. After confirmation of the needle position with EUS, thermal energy is delivered. In case of larger lesions, position of electrode may be changed under EUS guidance in order to ablate other areas within the lesion. Application of RFA may cause visual obscurities, therefore, it is advisable to ablate the technically challenging part of the tumor first (45). The recommended thermal energy for effective tumor ablation ranges from 60 to $100^{\circ} \mathrm{C}$ as temperature $>100$ may result in a higher risk of adverse events due to damage to surrounding structures (19). In addition to fragile pancreatic parenchyma that can be damaged by high temperatures, several anatomic challenges may hinder the use of RFA in the treatment of pancreatic cancer. These include the retroperitoneal location of the pancreas, a close relation of the pancreas to the duodenum, stomach, transverse colon and portal vein and involvement of the bile duct. Thus, there is a substantial risk of thermal damage to these structures if RFA is used for the pancreatic cancer (46). To avoid thermal damage to the surrounding vital structures, a circular area is spared at the tumor margins (47). Complete ablation of tumors located near large blood vessels is challenging because of the cooling effect generated by the blood flow (38). During the procedure, RFA-electrodes are positioned around the neoplastic tissue under direct visualization with an endoscope, thus minimizing the risk of damage to the adjacent tissues and blood vessels (38). Direct ablation of the entire tumor may not be feasible in cases of retroperitoneal extension and vascular invasion of the pancreatic tumor (46). Ablation may also prove to be difficult during laparotomy, particularly if liver metastases are found that were not detected before procedure (46).

RFA with subsequent stent placement has been successfully used to re-canalize biliary or pancreatic ducts that were obstructed by unresectable tumors (36). Indeed, ductal decompression with stenting is considered standard of care 
TABLE 2 | Studies demonstrating the efficacy and safety of endoscopic ultrasound guided ablation therapies for unresectable pancreatic cancer.

\begin{tabular}{|c|c|c|c|c|c|c|c|c|c|c|c|c|}
\hline \multirow[t]{2}{*}{ References } & \multirow{2}{*}{$\begin{array}{c}\text { Total } \\
\text { patients }(n)\end{array}$} & \multirow{2}{*}{$\begin{array}{c}\text { Age } \\
\text { (mean) }\end{array}$} & \multirow{2}{*}{$\begin{array}{c}\text { No. of } \\
\text { tumors }(n)\end{array}$} & \multirow{2}{*}{$\begin{array}{l}\text { Types of pancreatic } \\
\text { tumor }\end{array}$} & \multirow{2}{*}{$\begin{array}{l}\text { Size of tumor } \\
(\mathrm{mm}) \text { (mean) }\end{array}$} & \multirow{2}{*}{$\begin{array}{l}\text { Approach of } \\
\text { EUS Ablation }\end{array}$} & \multirow{2}{*}{$\begin{array}{l}\text { Ablation } \\
\text { sessions/ } \\
\text { lesions }\end{array}$} & \multirow{2}{*}{$\begin{array}{l}\text { Technical } \\
\text { success } n \\
(\%)\end{array}$} & \multicolumn{2}{|c|}{ Clinical success $n(\%)$} & \multirow[t]{2}{*}{ Adverse events ( $n$ ) } & \multirow{2}{*}{$\begin{array}{c}\text { Follow up } \\
\text { (mean months) }\end{array}$} \\
\hline & & & & & & & & & $\begin{array}{l}\text { Resolution of } \\
\text { symptoms }\end{array}$ & $\begin{array}{l}\text { Resolution/ } \\
\text { decrease in } \\
\text { tumor size }\end{array}$ & & \\
\hline $\begin{array}{l}\text { Arcidiacono et al. } \\
\text { (57) }\end{array}$ & 16 & ${ }^{*} 61.9$ & 16 & LAPDAC & 35.7 & EUS-RFA & $16 / 16$ & 16/22 (73) & - & 6/6 (100) & $\begin{array}{l}\text { Abdominal pain (3), } \\
\text { Bleeding (1), } \\
\text { Hyperamylasemia (1), } \\
\text { Obstructive jaundice (2), } \\
\text { Duodenal strictures (1) }\end{array}$ & 6 \\
\hline Levy et al. (58) & 5 & 66 & 5 & Insulinoma & 15 & EUS-EA & $11 / 5$ & $5 / 5(100)$ & $5 / 5(100)$ & NA & None & 13 \\
\hline Pai et al. (59) & 7 & ${ }^{*} 69$ & 7 & PDAC & 35.2 & EUS-RFA & $3^{*}$ & $7 / 7(100)$ & - & 7/7 (100) & Pancreatitis & $3-6$ \\
\hline Wang et al. (60) & 3 & 62.7 & 3 & $\begin{array}{l}\text { Unresectable } \\
\text { pancreatic cancer }\end{array}$ & 37.3 & EUS-RFA & $4 / 3$ & 3/3 (100) & 3/3 (100) & 3/3 (100) & None & 1.5 \\
\hline Park et al. (61) & 11 & 52.5 & 14 & $\begin{array}{l}\text { NNET (9), Insulinoma } \\
\text { (2) }\end{array}$ & 12.3 & EUS-EA & $18 / 14$ & $11 / 11(100)$ & $2 / 2(100)$ & 13/13 (100) & $\begin{array}{l}\text { Abdominal pain (1), } \\
\text { Pancreatitis (3), Pancreatic } \\
\text { duct stenosis (1). }\end{array}$ & 12 \\
\hline Song et al. (39) & 6 & ${ }^{*} 62$ & 6 & LAPDAC & 38 & EUS-RFA & $8 / 6$ & $6 / 6(100)$ & - & $6 / 6(100)$ & Abdominal pain (2) & $2-6$ \\
\hline Lakhtakia et al. (62) & 3 & 45 & 6 & Insulinoma & - & EUS-RFA & $9 / 3$ & $3 / 3(100)$ & $3 / 3(100)$ & 2/3 (67) & None & $11-12$ \\
\hline Paik et al. (63) & 8 & *55 & 8 & $\begin{array}{l}\text { NNET (2), Insulinoma } \\
\text { (3), Gastrinoma (1), } \\
\text { SPN (2) }\end{array}$ & 15 & EUS-EA & $8 / 8$ & 8/8 (100) & 4/4 (100) & 6/8 (75) & Abdominal pain (2) & 16.5 \\
\hline Qin et al. (64) & 7 & NA & 7 & Insulinoma & $8-34$ & EUS-LI & $11 / 11$ & $11 / 11(100)$ & $7 / 7(100)$ & NA & None & $1-18$ \\
\hline Di Matteo et al. (65) & 9 & ${ }^{\star} 74.7$ & 09 & LAPDAC & 35.4 & EUS-LA & 9/9 & 9/9 (100) & - & 9/9 (100) & $\begin{array}{l}\text { Pseudocyst (3), } \\
\text { Hyperamylasemia (2) }\end{array}$ & 7.4 \\
\hline Crino el al. (40) & 8 & 67 & 08 & $\begin{array}{l}\text { LAPDAC (7), } \\
\text { Metastatic RCC (1) }\end{array}$ & 36 & EUS-RFA & $12 / 8$ & $8 / 8(100)$ & - & $8 / 8(100)$ & $\begin{array}{l}\text { Abdominal pain (3), } \\
\text { Hyperamylasemia (1) }\end{array}$ & 6 \\
\hline Choi et al. (66) & 10 & $21-71$ & 10 & $\begin{array}{l}\text { NNET (7), Insulinoma } \\
\text { (1), SPN (2) }\end{array}$ & 20 & EUS-EA & $16 / 10$ & 10/10 (100) & 1/1 (100) & $10 / 10(100)$ & $\begin{array}{l}\text { Abdominal pain (1), } \\
\text { Pancreatitis (1) }\end{array}$ & 42 \\
\hline Scopelliti et al. (67) & 10 & $* * 50-71$ & 10 & LAPDAC & 25-75 & EUS-RFA & $14 / 10$ & 10/10 (100) & - & 9/10 (90) & $\begin{array}{l}\text { Asymptomatic ascites (2), } \\
\text { Peripancreatic effusion (2) }\end{array}$ & 1 \\
\hline Barthet el al. (68) & 12 & 59.9 & 14 & NNET & 13.1 & EUS-RFA & - & 12/12 (100) & - & 12/14 (87.5) & $\begin{array}{l}\text { Bacteremia (1), Pancreatic } \\
\text { duct stenosis (1) }\end{array}$ & 12 \\
\hline Oleinikov el al. (69) & 18 & 60.4 & 27 & $\begin{array}{l}\text { NNET (11), Insulinoma } \\
\text { (7) }\end{array}$ & 14.3 & EUS-RFA & - & 26/27 (96.2) & 7/7 (100) & $25 / 27(92.5)$ & Pancreatitis (2) & $2-21$ \\
\hline $\begin{array}{l}\text { Matsumoto et al. } \\
\text { (70) }\end{array}$ & 5 & **55-74 & 5 & NNET & 10 & EUS-EA & $8 / 5$ & $5 / 5(100)$ & - & 4/5 (80) & None & 12 \\
\hline Oh et al. (71) & 13 & ${ }^{*} 60$ & 13 & $\begin{array}{l}\text { Pancreatic serous } \\
\text { cystic neoplasms }\end{array}$ & $50^{*}$ & EUS-RFA & $19 / 13$ & 13/13 (100) & 13/13 (100) & 8/13 (61.5) & Abdominal pain (1) & $9.21^{*}$ \\
\hline
\end{tabular}

NA, not available; LAPDAC, locally advanced pancreatic ductal adenocarcinoma; NNET, non-functional neuroendocrine tumor; SPN, serous pancreatic neoplasm; H, head; BNT, body neck and tail; EUS, endoscopic ultrasound; RFA, radiofrequency ablation; EA, ethanol ablation; LI, lauromacrogol injection; LA, laser ablation.

*Median.

${ }^{*}$ Range. 
in patients with malignant obstruction of biliary or pancreatic ducts due to unresectable tumors, however, stents are often prone to occlusion $(23,24,48-50)$. When RFA is combined with stenting, specifically in these circumstances, stent patency is prolonged, presumably by reducing tumor volume and due to immunomodulatory effects, halting tumor regrowth (50-52). Though RFA combined with stenting is safe and prolongs stent patency, reports on the mortality benefits of this combination are conflicting $(53,54)$. Preoperative abdominal CT-scans are considered to be the standard of care in order to determine the exact location of the tumor, its dimensions, the presence or absence of abdominal metastasis and vascular invasion (55). Though there are multiple approaches to access the pancreas including transgastric or transduodenal endoscopy, open laparotomy or percutaneous approach, an endoscopic approach remains the most feasible and minimally invasive approach and has been shown to provide superior outcomes (56).

\section{Safety and Adverse Events}

Endoscopic-RFA for unresectable pancreatic cancer is a relatively safer approach with a high technical and clinical success rate and less risks of procedure-related mortality and adverse events (Table 2) (39, 40, 57-71). A recent meta-analysis of 14 studies with 158 patients has shown a pooled clinical success rate of EUS-RFA 83.5\% [95\% confidence interval (CI) 67.9-92.4\%] while adverse events rate of $32.2 \%$ (95\% CI 19.4-48.4\%) with majority of adverse events managed medically (72). In another large meta-analysis of 13 studies with 127 patients, Dhaliwal et al. demonstrated a very high pooled technical success rate (98\%), pooled clinical success rate (84.5\%) and safety profile of EUS-RFA in the management of unresectable pancreatic cancer (73). In this meta-analysis, the overall adverse events rate 1 week after EUSRFA was $13.4 \%$, with commonly reported adverse events being abdominal pain $8.81 \%$ (95\% CI, 2.72-16.88) followed by bleeding and pancreatitis observed in 1 patient each while perforation or procedure-related infections were not reported in any of the patients (73). Multiple small prospective and retrospective studies have shown promising results of EUS-RFA safety, its clinical and technical success as compared to intraoperative and percutaneous RFA (38-40, 60, 67, 74-76).

Radiofrequency hyperthermia has shown improvement in the palliation and response to the treatment by reducing the requirement of a high dose of chemotherapy $(74,77)$. Immense heating of the surrounding structures of the tumor, rather than damage caused by the tip of RFA probe, is associated with adverse events (55). Common adverse events of RFA are gastrointestinal hemorrhage, biliary leakage, duodenal injury, portal vein thrombosis and sepsis, while damage to normal pancreatic tissue may result in pancreatic ascites, pancreatic fistula, necrotizing pancreatitis and pseudocyst formation $(22,42$,

\section{REFERENCES}

1. Siegel RL, Miller KD, Jemal A. Cancer statistics, 2020. CA Cancer J Clin. (2020) 70:7-30. doi: 10.3322/caac. 21590
55). High morbidity (0-40\%) and mortality (0-25\%) rates were reported in the early phase of RFA application for pancreatic cancer (78). Later studies have shown fewer adverse events if the temperature and length of the dispensed energy are adjusted (79). It has been suggested that RFA temperature of $90^{\circ} \mathrm{C}$ causes fewer adverse events as compared to higher temperatures $(22,79,80)$. Probe distance of $10 \mathrm{~mm}$ from the duodenum and $15 \mathrm{~mm}$ from the portal and mesenteric vessels is recommended $(20,79)$. Continuous cooling of the duodenum using $100 \mathrm{ml} / \mathrm{min}$ saline at $5^{\circ} \mathrm{C}$ is also beneficial in reducing duodenal adverse events $(20,81)$. Some adverse events can also be reduced if gastric and biliary bypass procedures are performed concurrently (46). Taken together, EUS-RFA is a relatively safer modality and adjunct to chemotherapy and standard multidisciplinary management of unresectable pancreatic cancer. Multiple small studies have shown its safety because of high clinical success and less risk of procedure-related mortality and adverse events. However, there is a lack of data on improvement in the quality of life with the utility of RFA that prompts need for large randomized controlled trials to assess the efficacy of this modality in the management of unresectable pancreatic cancer.

\section{CONCLUSIONS}

Radiofrequency ablation has been increasingly applied in the management of unresectable pancreatic cancer. Both intraoperative and percutaneous RFA have shown the acceptable clinical and technical success rate, however clinical safety and risks of serious adverse events is concerning. With the development of more effective chemotherapy regimen and recent advancement of endoscopic devises, application of endoscopic RFA has shown promising results in the palliation of unresectable pancreatic cancer. EUS-RFA is relatively safer than intraoperative and percutaneous approach with a higher clinical and technical success rate and less risk of adverse events. Currently, large prospective studies to assess long term impact of RFA on quality of life and survival are lacking. This warrants the need for prospective clinical trials in the future to validate its role in pancreatic cancer.

\section{AUTHOR CONTRIBUTIONS}

MNY: manuscript writing, overall data collection, supervision, review, and revision. HE, AM, and FC: manuscript writing and overall data collection. AW: manuscript writing, review, and revision. MS and $\mathrm{KN}$ : literature search and data collection. All authors contributed to the article and approved the submitted version. doi: $10.1016 /$ j.ejca.2003.10.026 
3. Wray CJ, Ahmad SA, Matthews JB, Lowy AM. Surgery for pancreatic cancer: recent controversies and current practice. Gastroenterology. (2005) 128:1626-41. doi: 10.1053/j.gastro.2005. 03.035

4. Yang GY, Wagner TD, Fuss M, Thomas CR Jr. Multimodality approaches for pancreatic cancer. CA Cancer J Clin. (2005) 55:352-67. doi: $10.3322 /$ canjclin. 55.6 .352

5. Perone JA, Riall TS, Olino K. Palliative care for pancreatic and periampullary cancer. Surg Clin North Am. (2016) 96:1415-30. doi: 10.1016/j.suc.2016.07.012

6. Mirza AN, Fornage BD, Sneige N, Kuerer HM, Newman LA, Ames FC, et al. Radiofrequency ablation of solid tumors. Cancer J. (2001) 7:95-102.

7. Hadjicostas P, Malakounides N, Varianos C, Kitiris E, Lerni F, Symeonides P. Radiofrequency ablation in pancreatic cancer. HPB (Oxford). (2006) 8:61-4. doi: 10.1080/13651820500466673

8. Lin ZZ, Shau WY, Hsu C, Shao YY, Yeh YC, Kuo RN, et al. (2013). Radiofrequency ablation is superior to ethanol injection in early-stage hepatocellular carcinoma irrespective of tumor size. PLoS One 8:e80276. doi: 10.1371/journal.pone.0080276

9. Chiou YY, Hwang JI, Chou YH, Wang HK, Chiang JH, Chang CY. Percutaneous ultrasound-guided radiofrequency ablation of intrahepatic cholangiocarcinoma. Kaohsiung J Med Sci. (2005) 21:304-9. doi: 10.1016/S1607-551X(09)70125-1

10. Varshney S, Sewkani A, Sharma S, Kapoor S, Naik S, Sharma A, et al. Radiofrequency ablation of unresectable pancreatic carcinoma: feasibility, efficacy and safety. JOP. (2006) 7:74-8.

11. Dromi SA, Walsh MP, Herby S, Traughber B, Xie J, Sharma KV, et al. Radiofrequency ablation induces antigen-presenting cell infiltration and amplification of weak tumor-induced immunity. Radiology. (2009) 251:58-66. doi: 10.1148/radiol.2511072175

12. Teng LS, Jin KT, Han N, Cao J. Radiofrequency ablation, heat shock protein 70 and potential anti-tumor immunity in hepatic and pancreatic cancers: a minireview. Hepatobiliary Pancreat Dis Int. (2010) 9:361-5.

13. Girelli R, Frigerio I, Giardino A, Regi P, Gobbo S, Malleo G, et al. Results of 100 pancreatic radiofrequency ablations in the context of a multimodal strategy for stage III ductal adenocarcinoma. Langenbecks Arch Surg. (2013) 398:63-9. doi: $10.1007 / \mathrm{s} 00423-012-1011-\mathrm{z}$

14. LeVeen RF. Laser hyperthermia and radiofrequency ablation of hepatic lesions. Semin Intervent Radiol. (1997) 14:313-24.

15. Rhim H, Goldberg SN, Dodd GD III, Solbiati L, Lim HK, Tonolini M, et al. Essential techniques for successful radio-frequency thermal ablation of malignant hepatic tumors. Radiographics. (2001) 21:S17-35; discussion S36-19. doi: 10.1148/radiographics.21.suppl_1.g01oc11s17

16. Dubinsky TJ, Cuevas C, Dighe MK, Kolokythas O, Hwang JH. High-intensity focused ultrasound: current potential and oncologic applications. Am J Roentgenol. (2008) 190:191-9. doi: 10.2214/AJR.07.2671

17. Marrero JA, Kulik LM, Sirlin CB, Zhu AX, Finn RS, Abecassis MM, et al. Diagnosis, staging, and management of hepatocellular carcinoma: 2018 practice guidance by the American Association for the Study of Liver Diseases. Hepatology. (2018) 68:723-50. doi: 10.1002/hep.29913

18. de Baere T, Denys A, Wood BJ, Lassau N, Kardache M, Vilgrain V, et al. Radiofrequency liver ablation: experimental comparative study of watercooled versus expandable systems. Am J Roentgenol. (2001) 176:187-92. doi: 10.2214/ajr.176.1.1760187

19. Testoni S, Healey A, Dietrich C, Arcidiacono P. Systematic review of endoscopy ultrasound-guided thermal ablation treatment for pancreatic cancer. Endosc Ultrasound. (2020) 9:83-100. doi: 10.4103/eus.eus_74_19

20. Fegrachi S, Molenaar IQ, Klaessens JH, Besselink MG, Offerhaus JA, van Hillegersberg R. Radiofrequency ablation of the pancreas: two-week follow-up in a porcine model. Eur J Surg Oncol. (2014) 40:1000-7. doi: 10.1016/j.ejso.2013.11.001

21. Rombouts SJ, Vogel JA, van Santvoort HC, van Lienden KP, van Hillegersberg $\mathrm{R}$, Busch OR, et al. Systematic review of innovative ablative therapies for the treatment of locally advanced pancreatic cancer. Br J Surg. (2015) 102:182-93. doi: $10.1002 /$ bjs. 9716

22. Girelli R, Frigerio I, Salvia R, Barbi E, Tinazzi Martini P, Bassi C. Feasibility and safety of radiofrequency ablation for locally advanced pancreatic cancer. Br J Surg. (2010) 97:220-5. doi: 10.1002/bjs.6800
23. Matsui Y, Nakagawa A, Kamiyama Y, Yamamoto K, Kubo N, Nakase Y. Selective thermocoagulation of unresectable pancreatic cancers by using radiofrequency capacitive heating. Pancreas. (2000) 20:14-20. doi: 10.1097/00006676-200001000-00002

24. Wu Y, Tang Z, Fang H, Gao S, Chen J, Wang Y, et al. High operative risk of cool-tip radiofrequency ablation for unresectable pancreatic head cancer. J Surg Oncol. (2006) 94:392-5. doi: 10.1002/jso.20580

25. Hlavsa J, Procházka V, Andrasina T, Pavlík T, Penka I, Kala Z. Radiofrequency ablation in pancreatic cancer. Rozhl Chir. (2019) 98:441-9. doi: 10.33699/PIS.2019.98.11.441-449

26. Fegrachi S, Walma MS, de Vries JJJ, van Santvoort HC, Besselink MG, von Asmuth EG, et al. Safety of radiofrequency ablation in patients with locally advanced, unresectable pancreatic cancer: a phase II study. Eur J Surg Oncol. (2019) 45:2166-72. doi: 10.1016/j.ejso.2019. 06.008

27. Zou YP, Li WM, Zheng F, Li FC, Huang H, Du JD, et al. Intraoperative radiofrequency ablation combined with 125 iodine seed implantation for unresectable pancreatic cancer. World J Gastroenterol. (2010) 16:5104-10. doi: 10.3748/wjg.v16.i40.5104

28. Giardino A, Girelli R, Frigerio I, Regi P, Scopelliti F, Borin A, et al. Two hundred consecutive patients treated with radiofrequency ablation for stage III pancreatic cancer: results from a single institution. Eur J Surg Oncol. (2015) 41:S4-5. doi: 10.1016/j.ejso.2014.10.013

29. Paiella S, Salvia R, Girelli R, Frigerio I, Giardino A, D'Onofrio M, et al. Role of local ablative techniques (Radiofrequency ablation and Irreversible Electroporation) in the treatment of pancreatic cancer. Updates Surg. (2016) 68:307-11. doi: 10.1007/s13304-016-0385-9

30. D’Onofrio M, Crosara S, De Robertis R, Butturini G, Salvia R, Paiella S, et al. Percutaneous radiofrequency ablation of unresectable locally advanced pancreatic cancer: preliminary results. Technol Cancer Res Treat. (2017) 16:285-94. doi: 10.1177/1533034616649292

31. Rossi S, Viera FT, Ghittoni G, Cobianchi L, Rosa LL, Siciliani L, et al. Radiofrequency ablation of pancreatic neuroendocrine tumors: a pilot study of feasibility, efficacy, and safety. Pancreas. (2014) 43:938-45. doi: 10.1097/MPA.0000000000000133

32. Carrafiello G, Laganà D, Recaldini C, Dionigi G, Boni L, Bacuzzi A, et al. Radiofrequency ablation of a pancreatic metastasis from renal cell carcinoma: case report. Surg Laparosc Endosc Percutan Tech. (2008) 18:64-6. doi: 10.1097/SLE.0b013e3181592a13

33. Limmer S, Huppert PE, Juette V, Lenhart A, Welte M, Wietholtz H. Radiofrequency ablation of solitary pancreatic insulinoma in a patient with episodes of severe hypoglycemia. Eur $J$ Gastroenterol Hepatol. (2009) 21:1097-101. doi: 10.1097/MEG.0b013e3283 $23 \mathrm{~d} 70 \mathrm{e}$

34. Wu PH, Pan CC, Huang ZL, Li W, Zhao M, Zhou ZW. Percutaneous radiofrequency ablation approach through the spleen: initial case report for pancreatic tail gastrinoma. Chin J Cancer. (2010) 29:836-41. doi: $10.5732 / c j c .009 .10755$

35. Singh V, Varshney S, Sewkani A. Radiofrequency ablation of unresectable pancreatic carcinoma: 10-year experience from single centre. Pancreatology. (2011) 11:1-80.

36. Mizandari M, Kumar J, Pai M, Chikovani T, Azrumelashvili T, Reccia I, et al. Interventional radiofrequency ablation: a promising therapeutic modality in the management of malignant biliary and pancreatic duct obstruction. $J$ Cancer. (2018) 9:629-37. doi: 10.7150/jca.23280

37. Wagner M, Redaelli C, Lietz M, Seiler CA, Friess H, Buchler MW. Curative resection is the single most important factor determining outcome in patients with pancreatic adenocarcinoma. Br J Surg. (2004) 91:586-94. doi: 10.1002/bjs.4484

38. Spiliotis JD, Datsis AC, Michalopoulos NV, Kekelos SP, Vaxevanidou A, Rogdakis AG, et al. Radiofrequency ablation combined with palliative surgery may prolong survival of patients with advanced cancer of the pancreas. Langenbecks Arch Surg. (2007) 392:55-60. doi: 10.1007/s00423-0060098-5

39. Song TJ, Seo DW, Lakhtakia S, Reddy N, Oh DW, Park DH, et al. Initial experience of EUS-guided radiofrequency ablation of unresectable pancreatic cancer. Gastrointest Endosc. (2016) 83:440-3. doi: 10.1016/j.gie.2015. 08.048 
40. Crinò SF, D’Onofrio M, Bernardoni L, Frulloni L, Iannelli M, Malleo $\mathrm{G}$, et al. EUS-guided radiofrequency ablation (EUS-RFA) of solid pancreatic neoplasm using an 18-gauge needle electrode: feasibility, safety, and technical success. J Gastrointestin Liver Dis. (2018) 27:67-72. doi: 10.15403/jgld.2014.1121.271.eus

41. Signoretti M, Valente R, Repici A, Delle Fave G, Capurso G, Carrara S. Endoscopy-guided ablation of pancreatic lesions: technical possibilities and clinical outlook. World J Gastrointest Endosc. (2017) 9:41-54. doi: 10.4253/wjge.v9.i2.41

42. Pezzilli R, Ricci C, Serra C, Casadei R, Monari F, D'Ambra M, et al. The problems of radiofrequency ablation as an approach for advanced unresectable ductal pancreatic carcinoma. Cancers (Basel). (2010) 2:1419-31. doi: 10.3390/cancers2031419

43. Cantore M, Girelli R, Mambrini A, Frigerio I, Boz G, Salvia R, et al. Combined modality treatment for patients with locally advanced pancreatic adenocarcinoma. Br J Surg. (2012) 99:1083-8. doi: 10.1002/bjs.8789

44. Date RS, Siriwardena AK. Radiofrequency ablation of the pancreas. II: intra-operative ablation of non-resectable pancreatic cancer: a description of technique and initial outcome. JOP. (2005) 6:588-92.

45. Lakhtakia S, Seo DW. Endoscopic ultrasonography-guided tumor ablation. Dig Endosc. (2017) 29:486-94. doi: 10.1111/den.12833

46. Siriwardena AK. Radiofrequency ablation for locally advanced cancer of the pancreas. JOP. (2006) 7:1-4.

47. D’Onofrio M, Zamboni G, Faccioli N, Capelli P, Mucelli RP. Ultrasonography of the pancreas. 4. Contrast-enhanced imaging. Abdominal Imaging. (2007) 32:171-81. doi: 10.1007/s00261-006-9010-6

48. Lillemoe KD, Sauter PK, Pitt HA, Yeo CJ, Cameron JL. Current status of surgical palliation of periampullary carcinoma. Surg Gynecol Obstet. (1993) 176:1-10.

49. Nieveen van Dijkum EJ, Kuhlmann KF, Terwee CB, Obertop H, de Haes JC, Gouma DJ. Quality of life after curative or palliative surgical treatment of pancreatic and periampullary carcinoma. Br J Surg. (2005) 92:471-7. doi: $10.1002 /$ bjs.4887

50. Mizandari M, Pai M, Xi F, Valek V, Tomas A, Quaretti P, et al. Percutaneous intraductal radiofrequency ablation is a safe treatment for malignant biliary obstruction: feasibility and early results. Cardiovasc Intervent Radiol. (2013) 36:814-9. doi: 10.1007/s00270-012-0529-3

51. Widenmeyer M, Shebzukhov Y, Haen SP, Schmidt D, Clasen S, Boss A, et al. Analysis of tumor antigen-specific $\mathrm{T}$ cells and antibodies in cancer patients treated with radiofrequency ablation. Int J Cancer. (2011) 128:2653-62. doi: 10.1002/ijc.25601

52. Mizukoshi E, Yamashita T, Arai K, Sunagozaka H, Ueda T, Arihara F, et al. Enhancement of tumor-associated antigen-specific $\mathrm{T}$ cell responses by radiofrequency ablation of hepatocellular carcinoma. Hepatology. (2013) 57:1448-57. doi: 10.1002/hep. 26153

53. Kallis Y, Phillips N, Steel A, Kaltsidis H, Vlavianos P, Habib N, et al. Analysis of endoscopic radiofrequency ablation of biliary malignant strictures in pancreatic cancer suggests potential survival benefit. Dig Dis Sci. (2015) 60:3449-55. doi: 10.1007/s10620-015-3731-8

54. Wang J, Zhao L, Zhou C, Gao K, Huang Q, Wei B, et al. Percutaneous intraductal radiofrequency ablation combined with biliary stent placement for nonresectable malignant biliary obstruction improves stent patency but not survival. Medicine (Baltimore). (2016) 95:e3329. doi: 10.1097/MD.0000000000003329

55. Paiella S, Salvia R, Ramera M, Girelli R, Frigerio I, Giardino A, et al. Local ablative strategies for ductal pancreatic cancer (radiofrequency ablation, irreversible electroporation): a review. Gastroenterol Res Pract. (2016) 2016:4508376. doi: 10.1155/2016/4508376

56. Pandya GJ, Shelat VG. Radiofrequency ablation of pancreatic ductal adenocarcinoma: the past, the present and the future. World J Gastrointest Oncol. (2015) 7:6-11. doi: 10.4251/wjgo.v7.i2.6

57. Arcidiacono PG, Carrara S, Reni M, Petrone MC, Cappio S, Balzano G, et al. Feasibility and safety of EUS-guided cryothermal ablation in patients with locally advanced pancreatic cancer. Gastrointest Endosc. (2012) 76:1142-51. doi: 10.1016/j.gie.2012.08.006

58. Levy MJ, Thompson GB, Topazian MD, Callstrom MR, Grant CS, Vella A. USguided ethanol ablation of insulinomas: a new treatment option. Gastrointest Endosc. (2012) 75:200-6. doi: 10.1016/j.gie.2011.09.019
59. Pai M, Senturk H, Lakhtakia S, Reddy DN, Cicinnati V, Kabar I, et al. Endoscopic ultrasound guided radiofrequency ablation (EUS-RFA) for cystic neoplasms and neuroendocrine tumours of the pancreas. Gastrointest Endosc. (2013) 77:AB143-4. doi: 10.1016/j.gie.2013. 04.058

60. Wang D, Jin Z, Lei W, Leung JW, Li Z. Mo1524 endoscopic ultrasound guided radiofrequency ablation for the treatment of advanced pancreatic carcinoma. Gastrointest Endosc. (2013) 77:AB414. doi: 10.1016/j.gie.2013.03.272

61. Park DH, Choi J-H, Oh D, Lee SS, Seo D-W, Lee SK, et al. Endoscopic ultrasonography-guided ethanol ablation for small pancreatic neuroendocrine tumors: results of a pilot study. Clin Endosc. (2015) 48:158-64. doi: 10.5946/ce.2015.48.2.158

62. Lakhtakia S, Ramchandani M, Gupta R, Venugopal S, Galasso D, Reddy ND. Mo1494 EUS-guided radiofrequency ablation (EUS-RFA) using a novel internally cooled needle electrode for pancreatic insulinoma: a case series in humans. Gastrointest Endosc. (2015) 81:AB440. doi: 10.1016/j.gie.2015.03.824

63. Paik WH, Seo DW, Dhir V, Wang HP. Safety and efficacy of EUS-guided ethanol ablation for treating small solid pancreatic neoplasm. Medicine. (2016) 95:e2538. doi: 10.1097/MD.0000000000002538

64. Qin S, Liu Y, Ning H, Tao L, Luo W, Lu D, et al. EUS-guided lauromacrogol ablation of insulinomas: a novel treatment. Scand J Gastroenterol. (2018) 53:616-20. doi: 10.1080/00365521.2017.1402206

65. Di Matteo FM, Saccomandi P, Martino M, Pandolfi M, Pizzicannella M, Balassone V, et al. Feasibility of EUS-guided Nd:YAG laser ablation of unresectable pancreatic adenocarcinoma. Gastrointest Endosc. (2018) 88:16874.e161. doi: 10.1016/j.gie.2018.02.007

66. Choi JH, Seo DW, Song TJ, Park DH, Lee SS, Lee SK, et al. Endoscopic ultrasound-guided radiofrequency ablation for management of benign solid pancreatic tumors. Endoscopy. (2018) 50:1099-104. doi: 10.1055/a-0583-8387

67. Scopelliti F, Pea A, Conigliaro R, Butturini G, Frigerio I, Regi P, et al. Technique, safety, and feasibility of EUS-guided radiofrequency ablation in unresectable pancreatic cancer. Surg Endosc. (2018) 32:4022-8. doi: 10.1007/s00464-018-6217-x

68. Barthet M, Giovannini M, Lesavre N, Boustiere C, Napoleon B, Koch S, et al. Endoscopic ultrasound-guided radiofrequency ablation for pancreatic neuroendocrine tumors and pancreatic cystic neoplasms: a prospective multicenter study. Endoscopy. (2019) 51:836-42. doi: 10.1055/a-082 4-7067

69. Oleinikov K, Dancour A, Epshtein J, Benson A, Mazeh H, Tal I, et al. Endoscopic ultrasound-guided radiofrequency ablation: a new therapeutic approach for pancreatic neuroendocrine tumors. J Clin Endocrinol Metab. (2019) 104:2637-47. doi: 10.1210/jc.2019-00282

70. Matsumoto K, Kato H, Tsutsumi K, Mizukawa S, Yabe S, Seki H, et al. Efficacy and safety of endoscopic ultrasound-guided ethanol ablation therapy for pancreatic neuroendocrine tumors. Acta Med Okayama. (2016) 70:313-6. doi: 10.18926/AMO/54511

71. Oh D, Ko SW, Seo DW, Hong SM, Kim JH, Song TJ, et al. Endoscopic ultrasound-guided radiofrequency ablation of pancreatic microcystic serous cystic neoplasms: a retrospective study. Endoscopy. (2020). doi: 10.1055/a-1250-7786. [Epub ahead of print].

72. Zhang L, Tan S, Huang S, Zhong C, Lü M, Peng Y, et al. The safety and efficacy of endoscopic ultrasound-guided ablation therapy for solid pancreatic tumors: a systematic review. Scand J Gastroenterol. (2020) 55:1121-31. doi: 10.1080/00365521.2020.1797870

73. Dhaliwal A. Endoscopic ultrasound radiofrequency ablation demonstrates high success for pancreatic tumors. In: American College of Gastroenterology Annual Meeting. San Antonio, TX (2019).

74. Goldberg SN, Mallery S, Gazelle GS, Brugge WR. EUS-guided radiofrequency ablation in the pancreas: results in a porcine model. Gastrointest Endosc. (1999) 50:392-401. doi: 10.1053/ge.1999.v50.98847

75. Carrara S, Arcidiacono PG, Albarello L, Addis A, Enderle MD, Boemo C, et al. Endoscopic ultrasound-guided application of a new hybrid cryotherm probe in porcine pancreas: a preliminary study. Endoscopy. (2008) 40:321-6. doi: 10.1055/s-2007-995595

76. Pai M, Yang J, Zhang X, Jin Z, Wang D, Senturk H, et al. PWE-055 Endoscopic ultrasound guided radiofrequency ablation (EUS-RFA) for pancreatic ductal adenocarcinoma. Gut. (2013) 62:A153. doi: 10.1136/gutjnl-2013-304 907.344 
77. Date RS, Biggins J, Paterson I, Denton J, McMahon RF, Siriwardena AK. Development and validation of an experimental model for the assessment of radiofrequency ablation of pancreatic parenchyma. Pancreas. (2005) 30:26671. doi: 10.1097/01.mpa.0000153334.65729.a6

78. Keane MG, Bramis K, Pereira SP, Fusai GK. Systematic review of novel ablative methods in locally advanced pancreatic cancer. World J Gastroenterol. (2014) 20:2267-78. doi: 10.3748/wjg.v20.i9.2267

79. Giardino A, Girelli R, Frigerio I, Regi P, Cantore M, Alessandra A, et al. Triple approach strategy for patients with locally advanced pancreatic carcinoma. HPB (Oxford). (2013) 15:623-7. doi: 10.1111/hpb.12027

80. Date RS. Current status of local ablative techniques in the treatment of pancreatic cancer. Pancreas. (2006) 33:198-9. doi: 10.1097/01.mpa.0000229006.39667.ea

81. Fegrachi S, Molenaar IQ, Klaessens JH, Besselink MG, Offerhaus JA, van Hillegersberg R. Radiofrequency ablation of the pancreas with and without intraluminal duodenal cooling in a porcine model. J Surg Res. (2013) 184:867-72. doi: 10.1016/j.jss.2013. 04.068

Conflict of Interest: The authors declare that the research was conducted in the absence of any commercial or financial relationships that could be construed as a potential conflict of interest.

Copyright (C) 2021 Yousaf, Ehsan, Muneeb, Wahab, Sana, Neupane and Chaudhary. This is an open-access article distributed under the terms of the Creative Commons Attribution License (CC BY). The use, distribution or reproduction in other forums is permitted, provided the original author(s) and the copyright owner(s) are credited and that the original publication in this journal is cited, in accordance with accepted academic practice. No use, distribution or reproduction is permitted which does not comply with these terms. 